\title{
Experimental research on processing incomplete spherical surfaces of machine parts
}

\author{
Andrei Katunin ${ }^{1}$, Mikhail Burnashov ${ }^{1,}$, Anton Tryastsin ${ }^{1}$, and Alexander Edapin ${ }^{1}$ \\ ${ }^{1}$ Orel State University named after I.S. Turgenev, 95 Komsomolskaya str., Orel, Russian Federation
}

\begin{abstract}
Improving the durability and reliability of such components as ball joints of cars is very important. The article presents experimental studies to determine surface roughness of incomplete spherical surfaces of machine parts.
\end{abstract}

\section{Introduction}

The lack of scientifically grounded methods for assigning technological parameters for rolling incomplete spherical surfaces of ball pins hinders their widespread implementation in production.

\section{Experimental studies}

For experimental studies to obtain mathematical models of the surface roughness dependence of the rolled head of the ball pins on processing modes, blanks made of 38XGHM GOST and $40 \mathrm{H}$ GOST steels, most often used in the production of automobile joints in Russia, were used.

Studies of the rolling process of ball pin heads, carried out earlier, showed that the course of machining is better for milled workpieces with roughness parameter $R_{a}=1-2 \mu \mathrm{m}[1,2]$.

The main technological parameters for the formation of microgeometry of the rolled incomplete sphere of the ball pin head are [3]:

- tool rotation frequency $n_{u}$;

- workpiece rotation frequency $n_{3}$;

- rolling force $P$.

During experimental studies, the laboratory setup shown in Fig.1 was used.

A horizontal milling machine was used to install and adjust the rotational speed of the runner.

The ball pin rotation was driven by a special rolling head. In this case, an AC frequency converter was used, and the rotational speed was displayed by an indicator.

The required rolling force was set by adjusting the amount of compression of the knurling tool (the spindle of a horizontal milling machine) to the workpiece. The clamping force was recorded on the scale of the rolling rod of the runner spindle.

According to the standard technique, using a profilograph - a profilometer and

\footnotetext{
* Corresponding author: arshin721@yandex.ru
} 
appropriate computer software, the roughness of the processed ball pins was measured (Fig.2).

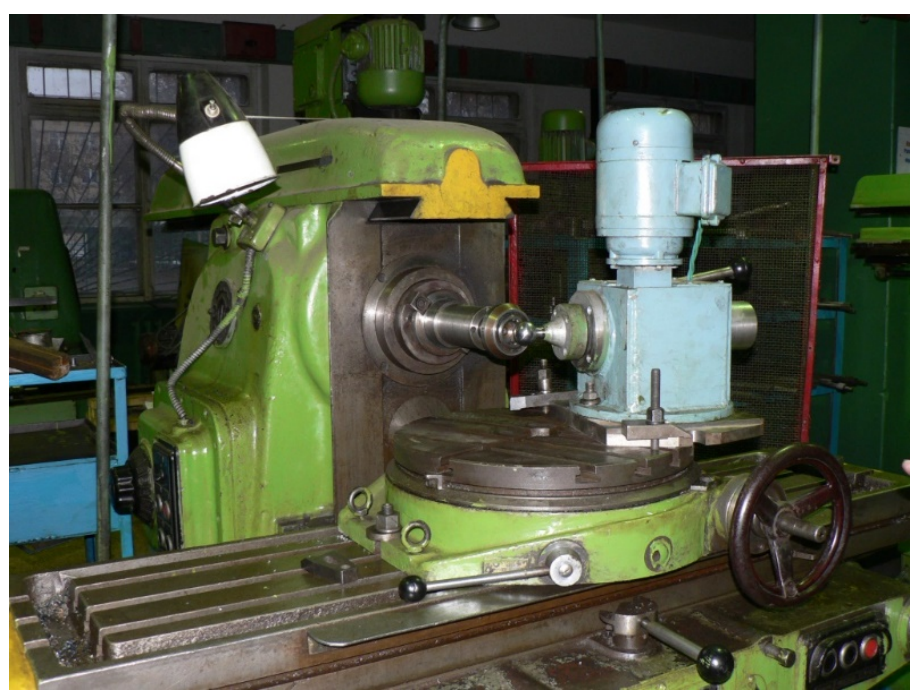

Fig. 1. Laboratory setup for researching the accuracy and quality of rolling ball pin heads (patent 2276005 RF, B 24 B 39/04).

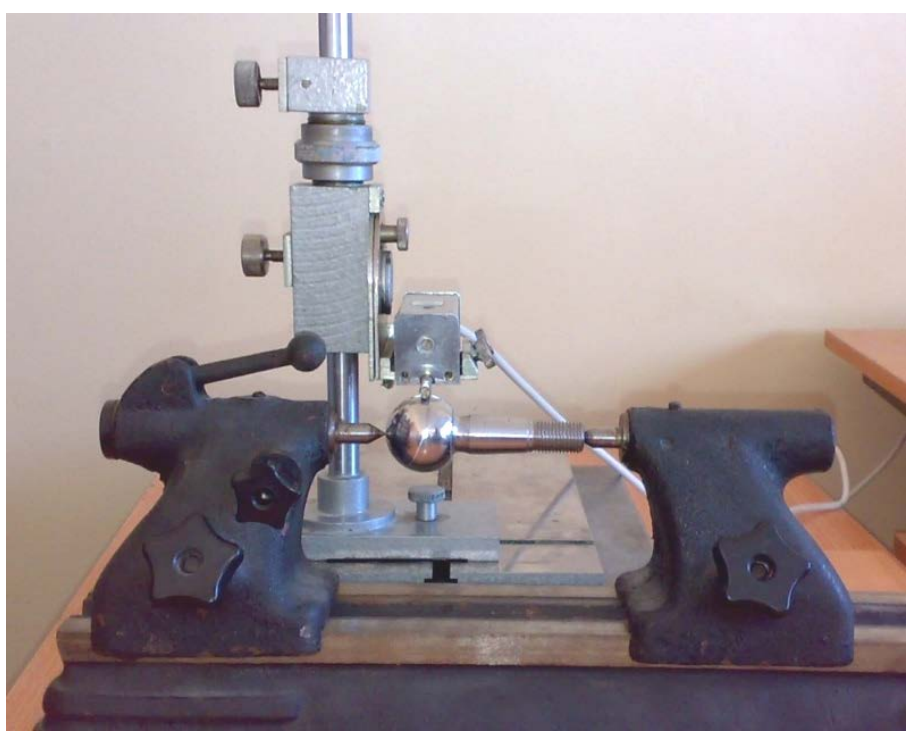

Fig. 2. Experimental setup for measuring roughness on the spherical surface of a ball pin.

As a result of processing experimental data to determine the parameters of surface roughness $\mathrm{Ra}$, the following dependences were obtained [4]:

- when rolling workpieces made of 38XGHM GOST:

$R_{a}=0,20295-0,000025 n_{u}+0,0014375 n_{3}-0,000041 P$, micron

- when rolling workpieces made of $40 \mathrm{H}$ GOST steel:

$R_{a}=0,20782-0,0000256 n_{u}+0,001472 n_{3}+0,000042 P$, micron 
Variance of the adequacy of the mathematical model is calculated using the following formula:

$$
s_{a d}^{2}=\frac{r}{n-m} \sum_{v=1}^{n}\left(\bar{y}_{v}-\hat{y}_{v}\right)^{2}
$$

If this parameter is determined when rolling blanks made of 38XGHM GOST steel:

made of $40 \mathrm{H}$ GOST steel:

$$
\begin{aligned}
& s_{a d}^{2}=\frac{3 \cdot 0,000071}{8-4}=0,000053 ; \\
& s_{a d}^{2}=\frac{3 \cdot 0,000074}{8-4}=0,000056 .
\end{aligned}
$$

This indicates the obvious adequacy of the obtained mathematical models without calculating the Fisher criterion.

Fig. 3-5 show graphs of the dependences of surface roughness of spherical heads of the ball pins on technological parameters of the rolling process.

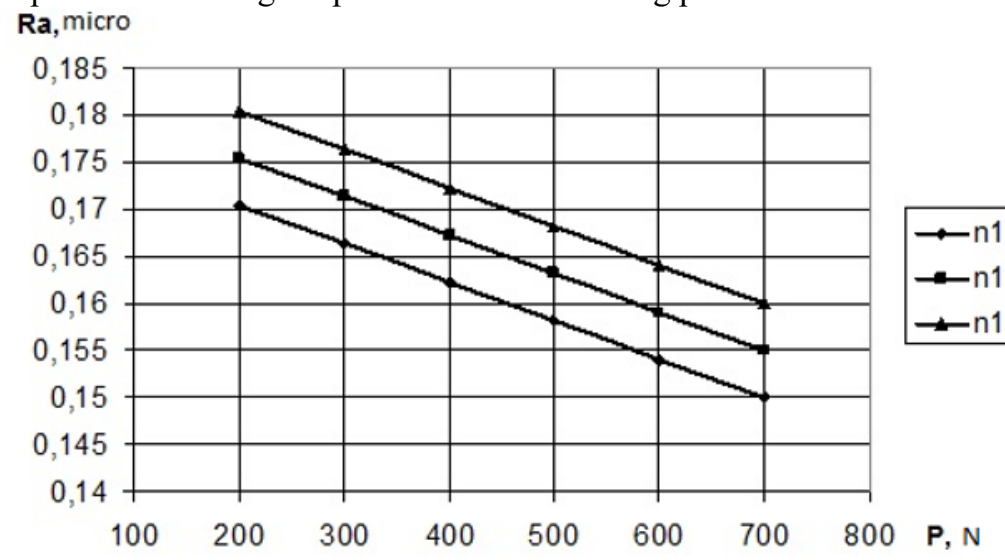

Fig. 3. Dependence of the surface roughness of workpieces made of 38XGHM GOST steel on the rolling force and tool rotation frequency (at a constant workpiece rotation speed $n=4 \mathrm{rev} / \mathrm{min}$ ).

\section{Ra, micro}

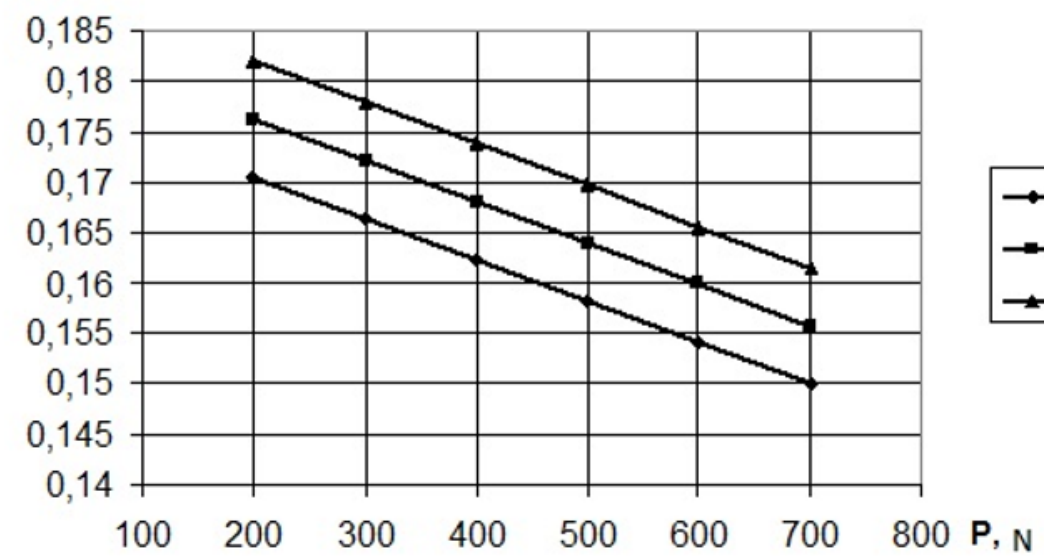

Fig. 4. Dependence of the surface roughness of workpieces made of 38XGHM GOST steel on the rolling force and workpiece rotation frequency (at a constant rolling speed $\mathrm{n}=1200 \mathrm{rev} / \mathrm{min}$ ). 


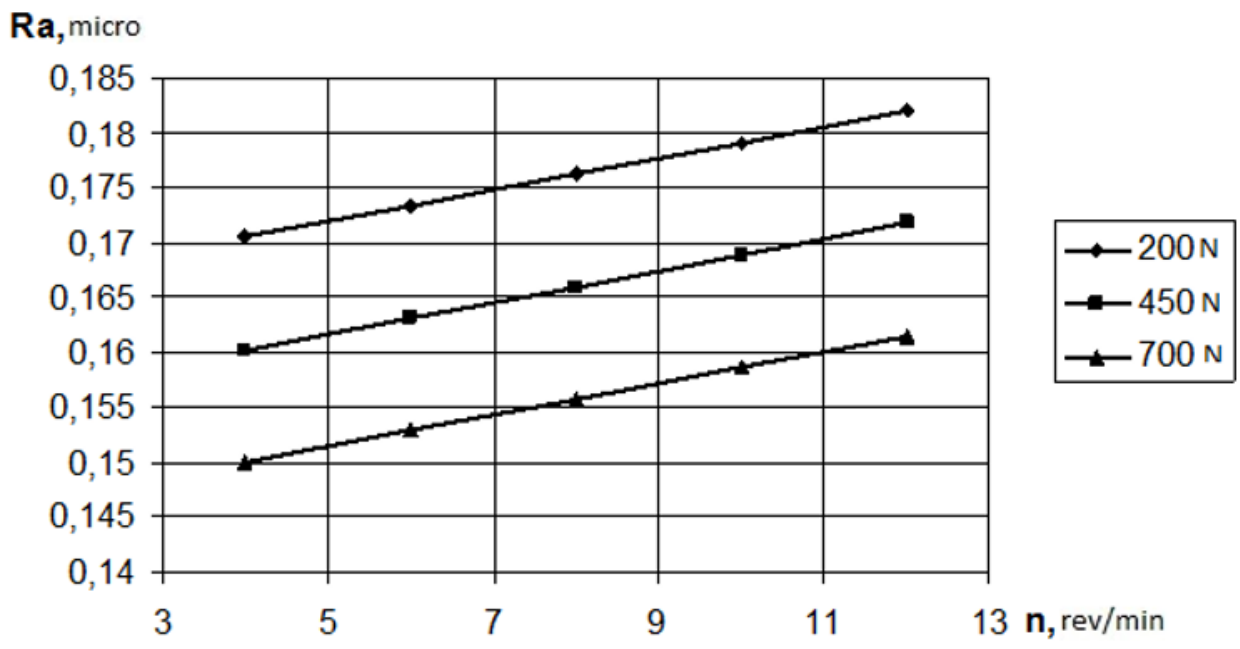

Fig. 5. Dependence of the surface roughness of workpieces made of $40 \mathrm{H}$ GOST steel on the force and speed of rolling (at a constant workpiece rotation frequency of $4 \mathrm{rev} / \mathrm{min}$ ).

\section{Conclusion}

Using well-known methods of calculating processing modes from the given roughness parameters [5], for the rolling process of heads of the ball pins, it is possible to scientifically assign optimal technological parameters.

\section{References}

1. Investigation of influence of the factors of technological process of planetary rolling on the microtopography of incomplete spherical surfaces of the ball finger heads / [V.K. Belov, I.G. Gun, A.Yu. Lednov, I.A. Mikhailovsky] // Hardware production in the $21^{\text {st }}$ century: Interuniversity collection of scientific. p. Magnitogorsk, 2001. pp. 164-173.

2. Katunin A.A. Ensuring accuracy of the shape and the given roughness of incomplete spherical heads of ball pins of automobile ball joints [Text]. A.A. Katunin, A.V. Katunin, N.N. Samoilov, A.M. Sidorov. Izvestia Orel State Technical University. Series Fundamental and Applied Problems of Engineering and Technology. - 2008. No. 2 (545). - pp. 56-58.

3. Belov V.K. Problems of surface microtopography measurement and their solution. Belov V.K., Lednov A.Yu. Processing of solid and layered materials: Interuniversity collection of scientific papers. Magnitogorsk: MGMA, 1996. pp. 95-102.

4. Katunin A.A. Mathematical model of the height of irregularities of the profile of an incomplete spherical surface during rolling with a full complement tool [Text]. A.A. Katunin, Yu.S. Stepanov, A.V. Katunin. Izvestia Orel State Technical University. Series Fundamental and Applied Problems of Engineering and Technology. - 2009. No. 2/274 (560). 110 p.

5. Bezyazychny V.F. Calculation of processing modes that provide a complex of parameters of the surface layer and processing accuracy. Bezyazychny V.F. Reference. Engineering journal. No. 9 (18), 1988. pp. 13-19. 